\title{
BYRON E O BYRONISMO NO CENTRO DA EPISTÉMÊ MODERNA
}

\author{
Pedro Augusto Pinto ${ }^{1}$ \\ Pedro Ivan Moreira de Sampaio²
}

Resumo: Este artigo tem como objetivo apresentar a identidade do eu lírico dito byroniano (seja na obra do poeta inglês, seja na obra de autores direta e sabidamente por ele influenciados) com a figura do homem, epicentro da epistémê moderna, consoante apresentado por Foucault em seus escritos dos anos de 1960. Tendo como eixo condutor o poema The Prophecy of Dante, acrescido de outras obras em verso, mostra-se na poesia a construção de um eu cujas características coincidem com a descrição do homem apresentada por Foucault, notoriamente, em As palavras e as coisas.

Palavras-chave: Byron - romantismo - Foucault - epistémê moderna - subjetividade.

\section{INTRODUÇÃO}

Existe uma expressão, provavelmente cunhada na França do século XIX, que designa uma forma muito específica de marginalidade. A alcunha se aplica fundamentalmente a uma certa prática de "autoexílio", uma existência que parece se constituir pela negação de seu próprio tempo, expressa em um modo de vida "escandaloso", "perverso", "pecaminoso", ou caracterizável por adjetivação semelhante. Trata-se de uma vivência de apartamento da sociedade, mas manifesta dentro de seu próprio seio; uma vida cuja simples presença parece desdenhar dos que a rodeiam pelo desapego inconsequente dos principais valores, morais ou materiais, de seu tempo. O termo que designa este curioso exílio manifesto na presença é o poète maudit ${ }^{3}$. Aquele cuja genialidade traz, em sua marca, o sentimento de constante

\footnotetext{
${ }^{1}$ Mestrando em Cultura e Literatura Russa na Universidade de São Paulo (USP) com estágio de pesquisa no Instituto de Literatura Mundial Górki da Academia Russa de Ciências, é Bacharel em História pela Universidade de São Paulo (USP) com intercâmbio acadêmico na Universidade Estatal de Moscou e na St. Mary's University College (Londres - Reino Unido).

2 Bacharel em Direito pela Pontifícia Universidade Católica de São Paulo (PUC/SP) e em Filosofia pela Universidade de São Paulo (USP) com período de intercâmbio acadêmico na Université Paris Sorbonne (Paris IV). É mestre em Filosofia pela Universidade de São Paulo (USP) e doutorando em Filosofia em regime de dupla titulação na Université Paris Descartes (Paris V) e Universidade de São Paulo (USP).

${ }^{3} \mathrm{O}$ termo em si tem a autoria atribuída a Alfred de Vigny em seu romance Stello de 1832, onde o escritor designa os poetas como: “(...) la race toujours maudite par les puissants de la terre” (VIGNY, Stello, p. 66). A expressão
} 
inadequação, a sensação própria de ser um espírito aprisionado na matéria e cuja engenhosidade está fadada à incompreensão. Este poeta é aquele que aglutina em si o sublime da poesia com a devassidão da vida.

Em todo caso, não nos ocuparemos aqui da história ou a caracterização mais detalhada deste termo. Interessa-nos, como ponto de partida, um poema específico da autoria de um poeta tipicamente maldito, e cuja biografia, por vezes, parece misturar-se à sua obra: trata-se de George Gordon Byron, $6^{\circ}$ Barão Byron, ou simplesmente Lorde Byron, e seu poema publicado em 1821, The Prophecy of Dante.

A profecia de Dante

Poeta. Muitos são poetas que jamais a inspiração

Puseram por escrito - e os melhores, talvez;

Sentiram e viveram, mas sem concessão

Dos pensamentos seus a nenhum ser mais soez;

Comprimiram o deus em seu interior

E juntaram-se aos astros, sem lauréis na terra,

Mais felizes porém que aqueles que o estridor

Da paixão degenera, e cuja fama encerra

Suas fragilidades, os conquistadores

De alto renome, mas cheios de cicatrizes.

Muitos são poetas, mas do nome não senhores,

Pois que é a poesia mais do que buscar raízes

No bem ou mal ultra-emotivos e querer

Uma vida exterior além de nosso fado?

E novo Prometeu do novo homem ser,

Dando o fogo do céu e, tudo consumado,

Vendo o prazer da oferta pago, mas com dor,

E abutres roendo o coração do benfeitor,

Que, tendo dissipado dávida sem par,

Jaz encadeado num rochedo junto ao mar?4

em si só ganhou popularidade no final do século, fundamentalmente devido aos artigos de Paul Verlaine no Boletim Lutèce intitulados "Les poètes mandits".

${ }^{4}$ BYRON, Poemas, p. 112-113.

The prophecy of Dante

Canto the fourth

Many are Poets who have never penned

Their inspiration, and perchance the best:

They felt, and loved, and died, but would not lend

Their thoughts to meaner beings; they compressed

The God within them, and rejoined the stars

Unlaurelled upon earth, but far more blessed

Than those who are degraded by the jars

Of Passion, and their frailties linked to fame,

Conquerors of high renown, but full of scars.

Many are Poets but without the name; 
Com estes versos Byron inicia o quarto e último canto deste longo poema feito em homenagem a Dante Alighieri. Já em uma primeira leitura deste fragmento, é possível perceber a marca do poete mandit, renegado por uma sociedade cujos costumes arcaicos são incapazes de receber, apreciar ou mesmo compreender o conteúdo de sua poesia. Assim, não é de se estranhar a afirmação do poema, de que apenas "os poetas que não puseram sua inspiração por escrito" garantem seu lugar junto às estrelas, enquanto os demais são recompensados com o mesmo destino de Prometeu.

É possível, todavia, ler um pouco mais neste poema do lorde inglês do que essa crítica às recusas antiquadas de uma sociedade tacanha. Para isso, é preciso primeiro compreender certa dualidade apresentada no poema. Dualidade que coloca o leitor diante de duas figuras distintas de poeta: um real e um ideal, ou ainda um transcendente e outro imanente. Em todo caso, mais que se tratar de dois poetas, um que não se concretiza e o segundo que coloca seus versos no mundo, o que o trecho mencionado salienta é antes um plano transcendente de onde emana a poesia e um plano imanente de sua recepção. A figura do poeta que não "compartilha seus versos com nenhum ser mais mesquinho" não é o que interessa propriamente. Essa figura unívoca praticamente já habita o plano da transcendência e não é surpresa que tenha assegurado seu lugar numa constelação. Já o poeta, que rouba os versos dos deuses para iluminar os homens, este é o artista real, um ser híbrido, dividido, aprisionado na empiricidade do mundo, mas capaz de (re)significá-la com seu espírito transcendente produtor da poesia.

É desta dimensão dupla que nos ocuparemos aqui, buscando identificar, na dualidade do poeta, as mesmas características que Foucault destaca na descrição da figura moderna de homem, como um duplo empírico-transcendental.

[...] o limiar da nossa modernidade não está situado no momento em que se pretendeu aplicar ao estudo do homem métodos objetivos, mas no dia em que se constituiu um duplo empírico-transcendental a que se chamou bomem. ${ }^{5}$

\section{A MORTE: DELIMITAÇÃO DO FINITO}

For what is Poesy but to create

From overfeeling Good or Ill; and aim

At an external life beyond our fate,

And be the new Prometheus of new men,

Bestowing fire from Heaven, and then, too late,

Finding the pleasure given repaid with pain,

And vultures to the heart of the bestower,

Who, having lavished his high gift in vain,

Lies to his lone rock by the sea-shore?

\footnotetext{
${ }^{5}$ FOUCAULT, As palavras e as coisas, p. 439. Neste artigo optamos por inserir nas notas de rodapé os escritos e textos conforme encontrados na língua original: « [...] le seuil de notre modernité n'est pas situé au moment où on a voulu appliquer à l'étude de l'homme des méthodes objectives, mais bien le jour où s'est constitué un doublet empirico-transcendantal qu'on a appelé l'homme. » (FOUCAULT, Les Mots et les choses, p. 329-430).
} 
É verdade que a primeira figura do poeta apresentada no poema de Byron a Dante talvez seja "mais feliz" ou mesmo "melhor", mas o fato é que ela não passa da idealidade antes de sua concretização no mundo. É o segundo poeta, conduzido pelas paixões de seu corpo imanente, que exterioriza o verso do fundo de sua alma para a empiricidade da vida. Se a consequência disso é ter toda contingência do mundo lançada sobre si, se sua recompensa é ter o corpo "coberto de cicatrizes", é perder o domínio de sua produção, deixar de ser senhor de seu nome, fato é que esta sina é ao mesmo tempo o limite da poesia e sua condição de possibilidade. Byron prossegue esse Canto da seguinte maneira:

Pois bem, suportaremos. Mas tais Homens,

De um Intelecto de Força transcendente

Que se afasta do pó que nos consome,

Ou o faz arder na alma, independente

A forma de suas obras, ou seus nomes,

São bardos; o Bronze, o Mármore austero

Expressam tal poesia em seus semblantes

Igual ou mais que as páginas de Homero;

Um traço nobre apenas, num instante

Já diviniza a tela, a faz brilhar:

Num brilho a tudo tão sobrepujante

Que todos que se prostram em seu altar

Não pecam contra os Céus - que lá estão

Transfigurados. Vive só no ar

A prole da Poesia, a Criação

Seres e Ideia, do Eu projetados,

E nada pode mais; Divida, então,

$\mathrm{O}$ artista o louro e o risco, e rejeitado

Feneça em meio às vaias: Desespero

E Gênio, ah!, não raro vão atados. ${ }^{6}$

${ }^{6}$ BYRON, The complete works of Lord Byron: with a biographical sketch and notes, p. 463. Tradução nossa. Original:

So be it: we can bear. — But thus all they

Whose Intellect is an o'ermastering Power

Which still recoils from its encumbering clay

Or lightens it to spirit, whatsoe'er

The form which their creations may essay,

Are bards; the kindled Marble's bust may wear

More poesy upon its speaking brow

Than aught less than the Homeric page may bear;

One noble stroke with a whole life may glow,

Or deify the canvass till it shine

With beauty so surpassing all below,

That they who kneel to Idols so divine

Break no commandment, for high Heaven is

there 
Nesta continuação, o lorde inglês não apenas se inclui no texto como ainda o faz de forma desafiadora ao conclamar: "que seja: nós podemos suportar". O ponto é que o poeta se constitui como a figura de um espírito flamejante aprisionado em uma forma de argila, mas esta é sua natureza própria de bardo. Desafiar a adversidade do mundo com a beleza do verso é o devir deste ser. De modo que a contingência de um mundo mesquinho rejeita $o$ verso e isto intensifica o brilho da poesia. A dura imanência não é o outro do poeta, mas o todo do qual ele faz parte e, por isso, é, ao mesmo tempo, a possibilidade do poema. Não é, então, gratuito que "o desespero e o gênio são frequentemente conexos". A paixão temporal é, assim, a desgraça do poeta e a condição de existência do verso. É desta maneira que se pode afastar a ideia de que o poema apresenta duas concepções distintas de poeta, para compreender que ambas as figuras de poeta coexistem em um todo, a dualidade em questão habita um único ser, frágil e conflituoso, uma desarmoniosa conjunção de espírito e matéria.

O homem, na analítica da finitude, é um estranho duplo empírico-transcendental, porquanto é um ser tal que nele se tomará conhecimento do que torna possível todo conhecimento. $^{7}$

Para além desta figura do poeta, o principal elemento que se pode destacar da contingência à qual ele é sujeitado no poema é um tema marcante de toda a geração romântica inaugurada pelo lorde, ou das muitas para as quais Byron viria a exercer um papel central: trata-se do tema da morte, recorrente na obra destes escritores conhecidos como "ultrarromânticos". É evidente que esta temática não é, em si, uma novidade nas artes. A morte já apareceu com destaque, por exemplo, no século XV como sendo o termo final, o ponto inexorável do destino, uma presença desencarnada que ronda e pode pôr termo à toda vida. ${ }^{8}$ Naquela época, o retrato da morte, como uma figura esquelética portando um sorriso quase irônico, carregava em sua imagem o trágico do fim. Tratava-se da figuração de um riso que antevia o abismo, a histérica gargalhada ante a tragédia inevitável do vazio da morte. ${ }^{9}$

Transfused, transfigurated: and the line

Of Poesy, which peoples but the air

With Thought and Beings of our thought reflected,

Can do no more: then let the artist share

The palm, he shares the peril, and dejected

Faints o'er the labour unapproved - Alas!

Despair and Genius are too oft connected. $[\ldots]$

${ }^{7}$ FOUCAULT, As palavras e as coisas, p.439. «L'homme, dans l'analytique de la finitude, est un étrange doublet empirico-transcendantal, puisque c'est un être tel qu'on prendra en lui connaissance de ce qui rend possible toute connaissance » (FOUCAULT, Les Mots et les choses, p. 329).

${ }^{8}$ FOUCAULT, Histoire de la folie à l'âge classique, p. 30-31.

${ }^{9}$ Para citar apenas uma referência literária, pode-se destacar a obra de Guyot Marchant intitulada Danse Macabre. Este título, em verdade, marca todo um gênero presente na literatura, teatro escultura, mas, especialmente na pintura, e cujo expoente mais conhecido talvez seja o afresco no Cimetière dês Saints-Innocents em Paris. 
Já no século XIX, o reaparecimento do tema não se dá nestes termos. A morte no poema de Byron a Dante não se configura em um trágico término no vazio. É bem verdade que, se tomamos outro poema, talvez até mais famoso do lorde inglês, o Lines inscribed upon a cup formed from a skull, a morte vem carregada de ironia, e o riso reaparece no próprio cálice feito de um crânio, cheio de vinho, onde outrora brilhara a razão.

Versos Inscritos numa Taça Feita de um Crânio 10

Não, não te assustes: não fugiu o meu espírito

Vê em mim um crânio, o único que existe

Do qual, muito ao contrário de uma fronte viva,

Tudo aquilo que flui jamais é triste.

Vivi, amei, bebi, tal como tu; morri;

Que renuncie e terra aos ossos meus

Enche! Não podes injuriar-me; tem o verme

${ }^{10}$ BYRON, Poemas, p. 106-107.

Lines inscribed upon a cup formed from a skull

Start not — nor deem my spirit fled:

In me behold the only skull

From which, unlike a living head,

Whatever flows is never dull.

I lived, I loved, I quaff d, like thee:

I died: let earth my bones resign;

Fill up — thou canst not injure me;

The worm hath fouler lips than thine.

Better to hold the sparkling grape,

Than nurse the earth-worm's slimy brood;

And circle in the goblet's shape

The drink of Gods, than reptiles' food.

Where once my wit, perchance, hath shone,

In aid of others' let me shine;

And when, alas! our brains are gone,

What nobler substitute than wine?

Quaff while thou canst — another race,

When thou and thine like me are sped,

May rescue thee from earth's embrace,

And rhyme and revel with the dead.

Why not? since through life's little day

Our heads such sad effects produce;

Redeem'd from worms and wasting clay,

This chance is theirs, to be of use. 
Lábios mais repugnantes do que os teus.

Antes do que nutrir a geração dos vermes,

Melhor conter a uva espumejante;

Melhor é como taça distribuir o néctar

Dos deuses, que a ração da larva rastejante.

Onde outrora brilhou, talvez, minha razão,

Para ajudar os outros brilhe agora eu;

Substituto haverá mais nobre que o vinho

Se o nosso cérebro já se perdeu?

Bebe enquanto puderes; quando tu e os teus

Já tiverdes partido, uma outra gente

Possa te redimir da terra que abraçar-te,

E festeje com o morto e a própria rima tente.

E por que não? Se as fontes geram tal tristeza

Através da existência - curto dia -,

Redimidas dos vermes e da argila

Ao menos possam ter alguma serventia.

Em todo caso, mesmo nesse poema, não se está diante da figura da morte que aparecia nas Dances Macabres do século XV. A ironia do poema, que dá voz a uma taça feita de um crânio, não coloca o leitor diante do vazio da morte, mas apenas perante sua inevitabilidade. A taça esquelética enche-se de vinho e incita a celebração enquanto a vida permitir, tendo na morte um termo que deve instigar, antes de sua concretização inexorável, certo comportamento bonviant - com um colorido mais macabro, é verdade, ou mesmo com certa inconsequência. A questão é que a morte aparece no século XIX como o delimitar da temporalidade, como signo da finitude humana. Não se trata do anunciar de um termino no vazio, mas de demarcar um período de existência do homem; período que é, ao mesmo tempo, a evidência de sua contingência e a condição de possibilidade de suas ações.

A morte que corrói anonimamente a existência cotidiana do ser vivo é a mesma que aquela, fundamental, a partir da qual se dá a mim mesmo minha vida empírica ${ }^{11}$.

Tomando novamente o poema com o qual este artigo se iniciou, pode-se reforçar ainda mais esta abordagem do tema da finitude. A morte, já anunciada, do poeta, delimita precisamente sua existência contingente. $\mathrm{O}$ nascimento e a morte são as fronteiras temporais

${ }^{11}$ FOUCAULT, As palavras e as coisas, p.434. La mort qui ronge anonymement l'existence quotidienne du vivant, est la même que celle, fondamentale, à partir de quoi se donne à moi-même ma vie empirique» (FOUCAULT, Les Mots et les choses, p. 326). 
que demarcam o período no qual o poeta pode lançar, na imanência do mundo, um fragmento da poesia roubado pela transcendência da alma. É aproximadamente nestes termos que essa figura dupla do poeta aparece: uma existência que tem na finitude de seu corpo a primeira marca da contingência que limita seu espírito, mas que, justamente a partir disso, pode irromper em verso. Para além do próprio Byron, é possível observar reverberações desta experiência, de limitação da vida ante a infinitude do verso, no poema de um notável byroniano que foi Álvares de Azevedo:

Um cadáver de poeta

Que os nervos convulsivos inflamava

E ardia sem conforto...

O que resta? uma sombra esvaecida,

Um triste que sem mãe agonizava...

Resta um poeta morto!

Morrer! e resvalar na sepultura,

Frias na fronte as ilusões — no peito

Quebrado o coração!

Nem saudades levar da vida impura

Onde arquejou de fome... sem um leito!

Em treva e solidão!

$[\ldots]$

Morreu um trovador - morreu de fome.

Acharam-no deitado no caminho:

Tão doce era o semblante! Sobre os lábios

Flutuava-lhe um riso esperançoso.

E o morto parecia adormecido. ${ }^{12}$

Nas duas primeiras estrofes aparece a miséria da morte, em sua dicotomia com a riqueza da poesia, que se manifesta na dignidade de ter, em sua homenagem, um poema, forma que reproduz em verso a musicalidade da existência do poeta, permitindo lançar ao infinito o brilho que se esvaiu na matéria. É isto que se observa no segundo trecho destacado - a preservação daquilo que traz vida ao rosto morto, transformando a morte em mero sono.

Neste ponto, é cabível explicitar a identidade entre a finitude do homem, tratada por Foucault, com o delimitar da vida do poeta. Pois, é a composição do poeta por essa faceta, fundamentalmente delimitada entre os extremos do nascimento e da morte, que o coloca como uma figura precisa do homem moderno, passível de ser pensado justamente graças à sua natureza finita.

12 AZEVEDO, A lira dos vinte anos, p. 123-124. 
[...] o homem moderno - esse homem determinável em sua existência corporal, laboriosa e falante - só é possível a título de figura da finitude. A cultura moderna pode pensar o homem porque ela pensa o finito a partir dele próprio. ${ }^{13}$

\title{
O TEMPO DO POETA E O TEMPO DO MUNDO
}

Há outro elemento passível de ser apreendido da leitura do poema a Dante com o qual iniciamos este texto. Mas, para percebê-lo, é prudente primeiro mencionar brevemente uma crítica ao texto de Byron no ano de sua publicação. Os quatro cantos do The Prophecy of Dante foram publicados no ano de 1821 juntamente com os Cinco Atos do Marino Faliero, Doge of Venice. Naquele mesmo ano, o Britsh Review and London Critical Journal publicou um artigo analisando detalhadamente a tragédia e dedicando, ao fim, dois magros parágrafos ao poema. Nestes parágrafos finais o crítico afirma fundamentalmente o seguinte:

\begin{abstract}
Sobre a profecia de Dante, o poema anexo à tragédia, devemos dizer pouco. Não há nada de muito engenhoso ou original no projeto. É simplesmente a transformação de alguns incidentes da história italiana que aconteceram posteriormente à sua morte, em profecia colocada em sua boca durante sua vida. ${ }^{14}$
\end{abstract}

No artigo há ainda alguns comentários a respeito da forma do poema, que se utiliza da terza rima, tida ainda hoje como de difícil utilização em língua inglesa ${ }^{15}$. Aqui, os pontos de interesse são precisamente as profecias colocadas na boca de Dante. Como já pôde ser visto, o poema tem mais elementos do que destaca esta crítica, mas é verdade que, especialmente nos três primeiros Cantos do poema de Byron, Dante profetiza diversos acontecimentos históricos que viriam a ocorrer depois de sua morte. A questão é que contar a história de forma profética, ainda que literariamente, não é um feito menor.

Como já havia sido salientado ao se comentar o início do quarto canto do poema, The Prophecy of Dante destaca a sina do poeta, hibrido de imanência e transcendência, fadado à mesquinhez de um mundo indigno da poesia e condenado a uma morte infame. Ocorre que essa "inadequação" do poeta se manifesta também no âmbito temporal. "O gênio não pertence a seu tempo" é um bordão que cabe perfeitamente aqui - justamente porque é este o tempo histórico de sua elaboração. É isso que emerge do ato de Byron colocar o "futuro" no discurso de Dante. Esta confusão temporal de contar ficcionalmente a história como profetização enunciada em um tempo passado evidencia que é o poeta que não habita propriamente o mesmo tempo do mundo. Delimitado pela sua finitude, ele convive com um

${ }^{13}$ FOUCAULT, As palavras e as coisas, p.438. « [...] l'homme moderne - cet homme assignable en son existence corporelle, laborieuse et parlante - n'est possible qu'à titre de figure de la finitude. La cuture moderne peut penser l'homme parce qu'elle pense le fini à partir de lui-même. » (FOUCAULT, Les Mots et les choses, p. 329)

14 "Upon the prophecy of Dante, the poem annexed to the tragedy, we shall say little. There is nothing very ingenious or original in the plan. It is simply a transformation of some of the incidents of Italian history which have taken place subsequently to his death, into prophecy put into his mouth during his life-time." (MURRAY, Marino Filiero, Doge of Venice. An Historical Tragedy, in Five Acts. With Notes - The Prophecy of Dante, a Poem. By Lord Byron, p. 451.Tradução nossa).

${ }^{15}$ ROWLEY, Byron's Prophecy of Dante and it's Form, Terza Rima, p. 5. 
mundo de história muito mais antiga que a sua própria, e com um prognóstico de futuro muito mais extenso que o de seu ser. Isso não significa, entretanto, que o poeta pertença a um tempo futuro, mas apenas que o desacordo entre sua delimitação temporal e a vastidão da história do mundo pode imbuir seu discurso da pretensão de alcançar um tempo que ele, por si só, não pode. Normalmente esta pretensão se funda na evidente longevidade que o texto pode ter, sendo capaz de perdurar muito além da vida daquele que o redigiu. "Pois que é a poesia mais do que [...] querer uma vida exterior além de nosso fado?’"16.

Em outros casos, o fenômeno tem como implicação a disparidade entre a vida em seu sentido estrito, cronológico, e a vida espiritual do poeta, esta sim, verdadeira, e que parece se desdobrar em um plano bastante distinto. O tema é recorrente na poesia romântica, e é formulado com agudeza em outro poema de Byron, Carta a Augusta, onde até mesmo a glória é relativizada diante desta outra dimensão existencial:

Carta a Augusta

$[\ldots]$

\section{XIII}

Com a falsa ambição que tinha eu a fazer?

Pouco com o amor, menos de tudo com o renome;

Mas vieram sem procura, e entraram de crescer

E me fizeram quanto podem - dar um nome.

Mas tal não era a meta para eu escolher;

De alvo mais nobre outrora eu tive a nobre fome.

Mas tudo terminou: - sou um a mais, somente,

Entre os milhões frustrados que partiram a frente.

\section{XIV}

Quanto ao futuro, o deste mundo poderia

Demandar-me somente mínima atenção;

A mim próprio sobrevivi por muito dia;

Perduro, e tantas coisas, tantas, já não são;

Meu tempo não foi sono, sob a tirania

De incessantes vigílias: tive eu a porção

De vida que podia a um séc'lo ter enchido

Antes que a quarta parte houvesse me servido.

$[\ldots]^{17}$

16 "For what is Poesy but to (...) aim at an external life beyond our fate" (BYRON, Poemas, p.112-113.)

17 BYRON, Poemas, p. 138-139.

Epistle to Augusta

$[\ldots]$

XIII

With false Ambition what had I to do?

Little with Love, and least of all with Fame;

And yet they came unsought, and with me grew, 
Voltando ao poema em homenagem a Dante, ao colocar uma profecia já concretizada na voz do autor da Divina Comédia, o poeta reforça a pretensão da imortalidade da escrita. Ele indica que não só o gênio, mas até a validade do texto pode ser reconhecida além de seu tempo. Mesmo um discurso profético, talvez meramente especulativo quando fora proferido, pode ser alçado à posição de verdade e reconhecido como tal em outro tempo. Byron conclui, então, o último Canto de seu poema da seguinte forma: "E quando a verdade acertar-lhes nos olhos / E deles fizer o profeta em seu túmulo"18. Dito em outros termos, a poesia pode, por fim, vencer a adversidade de seu tempo, a finitude do poeta; pode perdurar, tendo seu valor reconhecido quando o futuro vislumbrar o brilho que o passado não foi capaz de enxergar.

[...] o pensamento descobre que o homem não é contemporâneo do que o faz ser ou daquilo a partir do qual ele é [...] é porque o homem não é contemporâneo de seu próprio ser que as coisas vêm se dar com um tempo que lhes é próprio. ${ }^{19}$

Nestes termos, tem-se aqui mais um ponto de identidade deste eu lírico romântico com o homem moderno dos escritos arqueológicos de Foucault. Trata-se da natureza fundamentalmente intempestiva do homem, que o faz compreender o mundo a partir de sua temporalidade finita e distinta das coisas que o rodeiam. Nestes termos, sua inadequação temporal projeta na intelecção deste mundo um tempo distinto daquele do eu. A poesia, assim como os demais discursos ordenados por este homem, é a expressão direta desta subjetividade de tempo sempre inadequado ao do mundo, que se expressa ou age na esperança de irradiar seu ato a um momento que o próprio agente não pode atingir.

And made me all which they can make - a name,

Yet this was not the end I did pursue;

Surely I once beheld a nobler aim.

But all is over - I am one the more

To baffled millions which have gone before.

XIV

And for the future, this world's future may

From me demand but little of my care;

I have outliv'd myself by many a day,

Having surviv'd so many things that were;

My years have been no slumber, but the prey

Of ceaseless vigils; for I had the share

Of life which might have fill'd a century,

Before its fourth in time had pass'd me by.

[...]

18 "When Truth shall strike their eyes through many a tear, / And make them own the Prophet in his tomb."

(BYRON, The complete whorks of Lord Byron: with a biographical sketch and notes. p.465. Tradução nossa.)

${ }^{19}$ FOUCAULT, As palavras e as coisas, p. 462-463.« [...] la pensée découvre que l'homme n'est pas contemporain de ce qui le fait être, - ou de ce à partir de quoi il est [...] c'est parce que l'homme n'est pas contemporain de son être que les choses viennent se donner avec un temps qui leur est propre. » (FOUCAULT, Les Mots et les choses, p. 345-346). 


\section{O EU LÍRICO INEXPRIMÍVEL}

Um último aspecto ainda digno de nota sobre o poema do Lorde Byron diz respeito ao ser próprio do poeta. Como já foi visto, Byron constitui esta figura como um duplo de empiricidade e transcendência, como uma existência finita que não habita o mesmo tempo do mundo, e que busca em sua contingência temporal as condições para produzir um discurso com pretensão imortal. Mas, para além disso, este poeta byroniano é também impensável. Ele é um exercício reflexivo sobre si mesmo, em um movimento no qual o próprio poema não consegue captá-lo para além desta natureza duplicada. Isso talvez pela dificuldade, em si, de o poeta, neste caso, ser tanto o objeto do texto quanto o seu redator. Em certa medida, Byron em sua obra flerta frequentemente com o nebuloso, com as brumas da Inglaterra, com os temas chamados de "obscuros". Mas, neste caso, isso vai além, talvez, destas imagens. É importante perceber que, justamente no referido quarto Canto do poema, quando Byron aborda diretamente a figura do poeta, longe de fundar uma definição certa e definitiva de seu ser, o que se produz é, antes, o questionamento deste próprio ser.

Este poeta byroniano é, então, ambiguamente aquele que fala e, simultaneamente, sobre o que não se pode plenamente falar. Trata-se de uma existência que, ao questionar-se sobre si própria, desloca o pensamento para esta região da penumbra, do impensado. É como se o poeta propriamente escapasse por entre as linhas do texto, e a referência a ele não consegue ir muito além de uma natureza duplicada e em constante inadequação com o mundo circundante. Em terras insulares ou continentais, ele parece insistir em escapar por entre as linhas dos versos - seus ou do próprio Byron, que se consagrou na formulação poética deste eu. É Lérmontov que, na Rússia tsarista, ecoava essa angústia ultrarromântica em seus versos de 1832 .

\footnotetext{
Não, não sou Byron, sou outro - aquele

Ainda desconhecido eleito,

Pelo mundo caçado, qual ele,

De alma russa, porém, e de peito.

Fui mais cedo, cedo hei de acabar,

Minha mente fará quase nada;

Em minha alma - um enorme mar -.

Jaz um fardo de esp'ranças quebradas.

Quem poderá, ó mar nevoento,

Os teus segredos revelar? Quem

Dirá à turba os meus pensamentos?

$\mathrm{Eu}$ - serei Deus, ou então ninguém! 20
}

\footnotetext{
${ }^{20}$ LÉRMONTOV, Sobránïesotchiniéniivtchetyriokhtomakh, p. 459. Tradução nossa. Texto original:

Нет, я неБайрон, я Аругой,

Ещёневедомыйизбранник,

Какон, гонимыймиромстранник,

Нотолькосрусскоюдушой.
} 
Nesta dimensão fundamentalmente impensável do poeta, novamente se encontra a identidade deste eu lírico com o homem da epistémê moderna foucaultiana. Assim como o poeta que escapa entre os versos, deixando transparecer apenas a duplicidade de sua natureza de bardo, o homem também, simultaneamente sujeito que conhece e objeto a conhecer, aparece aqui como fugidio, como o ponto em que o pensamento se redobra sobre si mesmo e encontra nessa duplicidade os limites de sua própria cognição.

Nas palavras de Foucault, "[...] o homem aparece com sua posição ambígua de objeto para um saber e de sujeito que conhece: soberano submisso, espectador olhado [...]". ${ }^{21}$ Esta dicotomia conflituosa o coloca como o eu lírico e ao mesmo tempo o herói da poesia. É esta ambiguidade fundante de sujeito e objeto que lhe permite ser tomado pelo saber, e simultaneamente faz com que este saber se dobre sobre si mesmo, não autorizando a apreensão plena deste duplo pelo discurso, não concedendo a seu respeito uma cognição para além de sua própria natureza duplicada.

\section{A EPISTÉMÊDE EMERGÊNCIA DO POETA}

É então no entrono desta figura moderna do homem que orbita uma série de saberes e discursos chamados, grosso modo, de modernos. Isso não significa que a partir do final do século XVIII todo o saber passou a ser determinado por este duplo empírico e transcendental ou que esta figura constitua em si um sistema fechado de pensamento que condiciona toda verdade. A noção aqui referenciada, a epistémê, indica mais um conjunto de relações entre os discursos de um dado período do que a determinação rígida de seus conteúdos. Trata-se de indicar como se constituem os saberes e como se ordenam os discursos, como estes se aglutinam instituindo critérios de cientificidade ou mesmo de formalização de sistemas de pensamento. Neste sentido a epistémê pode ser vista como relações que perpassam os saberes e permitem que estes se articulem de determinadas maneiras e não de outras.

Por epistémê entende-se, na verdade, o conjunto das relações que podem unir, em uma dada época, as práticas discursivas que dão lugar a figuras epistemológicas, a ciências, eventualmente a sistemas formalizados; o modo segundo o qual, em cada uma dessas formações discursivas, se situam e se realizam as passagens à epistemologização, à

\footnotetext{
Яранышеначах, кончуране, Мойумнемногосовершит;

ВАушемоей, каквокеане,

Надежлразбитыхгрузцежит.

Ктоможет, океанугрюмый,

10 Твоиизведатьтайны? Кто

Толпемоирасскажетдумы?

Я — илиБог - илиникто!
}

${ }^{21}$ FOUCAULT, As palavras e as coisas, p.430. «[...] l'homme apparait avec sa position ambiguë d'objet pour un savoir et de sujet qui connait : souverain soumis, spectateur regardé [...] » (FOUCAULT, Les Mots et les choses, p. 323). 
cientificidade, à formalização; a repartição desses limiares que podem coincidir, ser subordinados uns aos outros, ou estar defasados no tempo; as relações laterais que podem existir entre figuras epistemológicas ou ciências, na medida em que se prendam a práticas discursivas vizinhas mas distintas. ${ }^{22}$

Além deste conjunto de relações que articulam os saberes em um dado tempo, a noção de epistémê diz respeito também à certa regularidade que pode ser apreendida na constituição de cada discurso, bem como à maneira de articulação entre os diferentes saberes, tudo em um mesmo período histórico. Não se trata propriamente de uma racionalidade comum que transpassa a constituição de todos os discursos, mas da apreensão de uma regularidade discursiva constitutiva do modo de pensar.

A epistémê não é uma forma de conhecimento, ou um tipo de racionalidade que, atravessando as ciências mais diversas, manifestaria a unidade soberana de um sujeito, de um espírito ou de uma época; é o conjunto das relações que podem ser descobertas, para uma época dada, entre as ciências, quando estas são analisadas no nível das regularidades discursivas. ${ }^{23}$

Esta regularidade, expressa no bojo das relações discursivas de um dado tempo e que não tem o condão de determinar o conteúdo do que se pensa, opera, por outro lado, certa delimitação de tudo o que pode ser pensado. Trata-se, em certo sentido, do estabelecimento de limites, de demarcar fronteiras ao pensar, de estabelecer este espaço do que pode ser pensado em um dado tempo, mas sem indicar propriamente uma determinação dos objetos pensados. A epistémê atua, assim, na ordem da delimitação, da demarcação do que é possível. É cabível destacar ainda que nesta região delimitada há uma pluralidade de possibilidades diversas de objetos pensáveis e de saberes sobre estes objetos, mas a epistémê tem sua atuação privilegiada na delimitação deste espaço, em excluir o que não pertence a ele, e não na determinação de tudo que efetivamente fecunda neste solo demarcado do possível.

A epistémê, ainda, como conjunto de relações entre ciências, figuras epistemológicas, positividades e práticas discursivas, permite compreender o jogo das coações e das limitações que, em um momento determinado, se impõem ao discurso [...] é aquilo

\footnotetext{
${ }^{22}$ FOUCAULT, $A$ arqueologia do saber, p. 231. «Par épistémè, on entend, en fait, l'ensemble des relations pouvant unir, à une époque donnée, les pratiques discursives qui donnent lieu à des figures épistémologuique, à des sciences, éventuellement à des systèmes formalisés ; le mode selon lequel, dans chacune de ces formations discursives, se situent et s'opèrent les passages à l'épistémologisation, à la scientificité, à la formalisation ; la répartition de ces seuils, qui peuvent entrer en coïncidence, être subordonnés les uns aux autres, ou être décalés dans le temps ; les rapports latéraux qui peuvent exister entre des figures épistémologiques ou des sciences dans la mesure où elles relèvent des pratiques discursives voisines mais distinctes. » (FOUCAULT, L'archéologie du savoir, p. 204-205). ${ }^{23}$ FOUCAULT, A arqueologia do saber, p. 231. «L'épistémè, ce n'est pas une forme de connaissance ou un type de rationalité qui, traversant les sciences les plus diverses, manifesterait l'unité souveraine d'un sujet, d'un esprit ou d'une époque ; c'est l'ensemble des relations qu'on peut découvrir, pour une époque donnée, entre les sciences quand on les analyse au niveau des régularités discursives. » (FOUCAULT, L’archéologie du savoir, p. 205).
} 
que na positividade das práticas discursivas, torna possível a existência das figuras epistemológicas e das ciências. ${ }^{24}$

De maneira sintética, a epistémê é, então, este solo de onde podem emergir os saberes, a referência na constatação das regularidades que marca os modos pelos quais os objetos são tomados. Ela é, por fim, percebida justamente no âmbito desta gramática dos discursos produzidos sobre os objetos em apreensão que emergem do solo delimitado de possibilidades.

Nestes termos, firmar o homem como o ponto central da epistémê moderna, significa, então, ordenar o saber e os discursos deste momento entre os dois polos deste duplo empírico/transcendental. É assim que se pode colocar como delimitação fundamental do conhecimento aquilo que o sujeito transcendente pode tomar como objeto. No mesmo sentido, limitam-se os objetos do conhecimento como sendo tudo aquilo que o homem, em sua empiricidade, pode apreender.

\begin{abstract}
Neste sentido, este homem, com seu poder de dar representação, é necessário à ordem do saber moderno como a superfície de projeção e de reflexão dessas formas positivas que se oferecem como elemento de sua existência empírica. ${ }^{25}$
\end{abstract}

Tal qual a figura do poeta byroniano, condição de possibilidade fundante do verso, o homem emerge no final do século XVIII como a possibilidade do conhecimento, como o produtor do saber. É neste sentido que se pode ler o eu lírico byroniano em sua profunda identidade com a figura do homem da epistémê moderna, tal qual caracterizada por Foucault. Sua dualidade é, assim, a condição de produção do verso, a possibilidade de sua composição, ao mesmo tempo em que fornece os limites de compreensão tanto do verso quanto do próprio poeta. No mesmo sentido, a figura do homem é a condição de possibilidade dos saberes modernos e é o ponto de ordenação do solo de onde fecundam as ciências humanas. Ao mesmo tempo, é este homem que traça, a partir de seus próprios limites de sujeito e objeto, a delimitação da intelecção de todos os saberes de seu tempo.

\title{
CONCLUSÃO
}

O motivo para a escolha dos trechos do Canto IV do poema de Byron a Dante e dos demais excertos poéticos foi a possibilidade de se ler, nas entrelinhas da reflexão sobre o poeta byroniano, a emergência de uma figura mais abrangente e de fundamental importância

\footnotetext{
${ }^{24}$ FOUCAULT, $A$ arqueologia do saber, p. 231-232.« [...] l'épistémè, comme ensemble de rapports entre des sciences, des figures épistémologiques, des positivités et des pratiques discursives permet de saisir le jeu des contraintes et des limitations qui, à un moment donné, s’imposent au discours [...] c'est ce qui dans la positivité des pratiques discursives, rend possible l'existence des figures épistémologique et des sciences. » (FOUCAULT, L'archéologie du savoir, p.205).

${ }^{25}$ No original : «En ce sens, cet homme, avec son pouvoir de donner de représentation, est requis dans l'ordre du savoir moderne comme la surface de projection et de réflexion de ces formes positives qui s'offrent comme l'élément de son existence empirique »(SABOT, Lire Les mots et les choses de Michel Foucault, p. 126).
} 
para todo o século XIX, a figura moderna do homem. Nas palavras de Foucault: "antes do fim do século XVIII o homem não existia [...]. É uma criatura muito recente que a demiurgia do saber fabricou há menos de 200 anos." 26

Este duplo empírico transcendental, delimitado por sua própria finitude, habitante de um mundo do qual ele não é contemporâneo, e, em certa medida, impensado, não é apenas o poeta de Byron, mas também o homem; a figura que desde o fim do século XVIII passou a ser o centro de todo um modo de pensar, de todo um solo de possibilidades para o saber, da epistémê moderna. ${ }^{27}$

Se o poeta de Byron é uma figura repartida entre um corpo temporal e a alma imortal, o homem é por sua vez um duplo capaz de apreender o mundo por sua dimensão empírica e ordenar este mundo para compreendê-lo no âmbito de seu espírito transcendente. Se o poeta é aquele que faz da fragilidade de sua delimitação temporal a condição mesma para a invenção do verso, o homem tem, em sua finitude, a demarcação e o móvel de toda ação possível. Se o poeta é este ser conflitante e inadequado com seu próprio tempo, o homem é por sua vez incapaz de ser plenamente contemporâneo do mundo que habita, presenciando sempre uma história de origem muito anterior à sua e prognóstico infinitamente mais longo que o seu próprio. Por fim, se a poesia não parece ser capaz de versar plenamente sobre a figura do poeta, limitando-se a descrever sua natureza híbrida, o pensamento, por sua vez, ao se redobrar sobre o homem, também não consegue ir muito além da sua duplicidade de empírico/transcendental, fazendo com que ele não possa ser tomado na transparência absoluta de um cogito, nem na objetividade pura de uma coisa. Nestes termos, o poeta só poderia ser homem, e o homem, em certo sentido, poeta.

\section{BYRON AND BYRONISME AT THE CENTER OF THE MODERN EPISTÉMÊ}

Abstract: This paper aimed to present the identity of the so-called Byronian lyric self (whether in the work of the English poet himself or in the work of authors directly and knowingly influenced by him) with the figure of man, epicenter of the modern episteme, as presented by Foucault in his writings of the 1960s. The construction of an I whose characteristics coincide with Foucault's description of man, as notoriously presented in The Order of Things, was thus shown in The Prophecy of Dante, which served as our main analytical axis, as well as in other works in verse.

Keywords: Byron - Romanticism - Foucault - modern episteme - subjectivity.

\section{REFERÊNCIAS BIBLIOGRÁFICAS}

AZEVEDO, A. A lira dos vinte anos. Porto Alegre: L\&PM Editores, 2001.

BYRON, George Gordon. The complete works of Lord Byron: with a biographical sketch and notes. New York: Thomas Y. Crowell Company Publishers, 1927.

${ }^{26}$ FOUCAULT, As palavras e as coisas, p. 425. "Avant la fin du XVIIIe siècle, l'homme n'existait pas. [...] C'est une toute récente créature que la démiurgie historique du savoir a fabriquée de ses mains, il y a moins de deux cents ans » (FOUCAULT, Les Mots et les choses, p.319).

${ }^{27}$ FOUCAULT, As palavras e as coisas, p. 430-432. Cf. FOUCAULT, Les Mots et les choses, p. 323-324. 
. Poemas. Tradução e organização por Péricles Eugênio da Silva Ramos. São Paulo: Hedra, 2008.

CAMPOS, H. Metalinguagem e outras metas. 4ª ed. São Paulo: Perspectiva, 2006.

CANDIDO, A. Estudo analítico do poema. 4a ed. São Paulo: Humanitas, 2004.

CASTRO, Eduardo. Vocabulário de Foucault: um percurso pelos seus temas, conceitos e autores. $1^{\mathrm{a}}$ edição. Belo Horizonte: Autêntica, 2009.

CHAUCIAY, R. Teoria do verso. São Paulo: Ed. McGraw-Hill, 1974.

EIKHENBAUM, B. "LiteratúrnaiaPozítsiiaLiérmontova”. In: O prózie, o poéziii: sbórnik statiéi,p. 94185. Leningrado:KhudójestvennaiaLiteratura, 1986.

FOUCAULT, Michel. Histoire de la folie à l'âge classique. Paris: Gallimard, 2011a. - História da loucura na idade clássica. Trad. José Teixeira Coelho Neto. São Paulo: Perspectiva, 2010.

. «La naissance d'un monde ». In: Dits et Ecrits I 1954 - 1975, p. 814-817. Paris: Gallimard, 2011a.

« L’archéologie du savoir ». In :CEuvres (tome II), Bibliothèque de la Pléiade. Paris: Gallimard, 2015.

. A arqueologia do saber. Trad. Luiz Felipe Baeta Neves. Rio de Janeiro: Forense, 2011b.

Les mots et les choses: une archéologie des sciences humaines. Paris: Gallimard, 2011c.

As palavras e as coisas: uma arqueologia das ciências humanas. Trad. Salma Tannus Muchail. São Paulo: Martins Fontes, 2007.

. «L'homme est-il mort ? In: Dits et Ecrits I 1954 -1975. Paris: Gallimard, 2001.

L'ordre du discours. Paris: Gallimard, 1971.

. Sur le façon d'écrite l'histoire. In: Dits et Écrits I, 1954-1975, p. 613-628. Paris: Gallimard, 2001.

GURIÉVITCH, A. “ProbliémanrávstvennogoideálavlírikeLiérmontova”.In: TvórtchestvoM. Iu. Liérmontova: 150 lietsodniá rojdiénïa, 1814-1964. Moscou: Naúka, 1964.

LÉRMONTOV, M. Sobránïesotchiniéniivtchetyriokhtomakh. v. I. Moscou: KhudójestvennaiaLiteratura, 1964.

MURRAY, John. "Marino Filiero, Doge of Venice. An Historical Tragedy, in Five Acts. With Notes - The Prophecy of Dante, a Poem. By Lord Byron”. In: The British Review and London Critical Journal (Vol. XV III). Printed for Baldwin, Cradock, and Joy. Paternoster-kow; and J. Hatchard and Son, Piccadilly. London, 1821. 
PINTO, P. A. "O problema da subjetividade na lírica de M. I. Lérmontov: apontamentos para uma investigação no âmbito da História da Cultura". In: SLOVO: Revista de estudos em Eslavística, v. 2, nº. 2.UFRJ, 2019. Disponível em: https://revistas.ufrj.br/index.php/slovo/article/view/23106/13706 .Acesso em 2019-09-10.

PONTE, L. da. "La Profezia di Dante di Lord Byron, tradotta in terza rima". In: The Literary and Scientific Repository and Critical Review (Vol. IV, No 07 e 08). New York: Published Quartely, 1822.

ROWLEY, Rosemarie. Byron's Prophecy of Dante and it's Form, Terza Rima. Irish Byron Society. Dublin. 2011. Disponível em: http://irishbyronsociety.ie/pdfs/dantie.pdf . Acesso em 08-08-2019.

RUEFF, Martin. "Notice: L'archéologie du savoir». In: Michel FoucaultEEuvres (tome II), Bibliothèque de la Pléiade. Paris : Gallimard, 2015.

SABOT, Philippe. Lire Les mots et les choses de Michel Foucault. Paris: PUF, 2006. . «Notice : Les mots et les choses ». In: Michel FoucaultCEuvres (tome I), Bibliothèque de la Pléiade. Paris: Gallimard, 2015.

SALIBA, E. As utopias românticas. 2ª ed. São Paulo: Estação Liberdade, 2003.

SAMPAIO, P. I. M. O momento marginalista: uma arqueologia do pensamento econômico do século XIX. 2019. Dissertação (Mestrado em Filosofia) - Faculdade de Filosofia, Letras e Ciências Humanas, Universidade de São Paulo, São Paulo, 2019. Disponível em: http://www.teses.usp.br/teses/disponiveis/8/8133/tde-09092019-170900/. Acesso em: 2019-0910.

VIGNY, Alfred. Stello. Paris: Ernest Flammarion, s/d.

WACHTEL, M. Introduction to Russian Poetry. Cambridge: Cambridge University Press, 2004. 